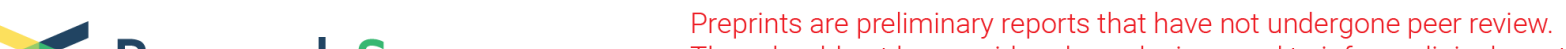

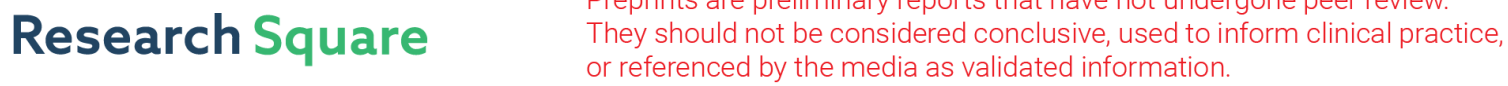 \\ Higher Prevalence of Obesity among Children with Functional Abdominal Pain Disorders
}

\section{Tut Galai}

Tel Aviv Sourasky Medical Center

\section{Hadar Moran-Lev}

Tel Aviv Sourasky Medical Center

Shlomi Cohen ( $\nabla$ shlomico@tlvmc.gov.il)

Dana-Dwek Children's Hospital https://orcid.org/0000-0002-6190-3217

\section{Amir Ben-Tov}

Tel Aviv Sourasky Medical Center

\section{Dina Levy}

Tel Aviv Sourasky Medical Center

\section{Yael Weintraub}

Tel Aviv Sourasky Medical Center

\section{Achiya Amir}

Tel Aviv Sourasky Medical Center

\section{Or Segev}

Tel Aviv Sourasky Medical Center

\section{Anat Yerushalmy-Feler}

Tel Aviv Sourasky Medical Center

\section{Research article}

Keywords: functional gastrointestinal disorders, children, irritable bowel syndrome, overweight, obesity

Posted Date: January 9th, 2020

DOI: https://doi.org/10.21203/rs.2.20433/v1

License: (c) (i) This work is licensed under a Creative Commons Attribution 4.0 International License. Read Full License

Version of Record: A version of this preprint was published at BMC Pediatrics on May 6th, 2020. See the published version at https://doi.org/10.1186/s12887-020-02106-9. 


\section{Abstract}

Background Functional abdominal pain (FAP) disorders are one of the most common gastrointestinal disorders in children. We aimed to define the association between obesity and functional abdominal pain (FAP) disorders and to assess differences between overweight/obese children and normal weight children with FAP disorders.

Methods We conducted a retrospective study of children (2-18 years old) with a clinical diagnosis of FAP who were followed-up in our pediatric gastroenterology unit between 1/2016-10/2018. FAP disorders were defined according to the ROME IV criteria. Body mass index (BMI) percentiles were defined by CDC standards. Patients with BMls $\geq 85 \%$ were designated as being overweight/obese. A healthy control group was obtained from the 2015-2016 Israel national health survey.

Results Data from 173 children with FAP disorders (median age 11.5 years, 114 females) were included. Seventy-one children (41\%) were classified as having abdominal pain-NOS, 67 (38.7\%) as having irritable bowel syndrome (IBS), and 35 (20.2\%) has having functional dyspepsia. Fifty-three children (30.6\%) were classified as being overweight/obese. Adolescents with FAP disorders had a significantly higher prevalence of overweight/obesity compared to controls ( $39.5 \%$ vs. $30 \%$, respectively, $p=0.04)$. Overweight FAP children were older [12.4 (range 9.8-15.3) vs. 10.8 (7.4-14.1) years, $p=0.04]$ and had more hospitalizations due to $\operatorname{FAP}(20.8 \%$ vs. $7.6 \%, p=0.01)$ compared to normal weight FAP children.

Conclusions Children with FAP had higher prevalence of overweight/obesity compared to healthy controls. Future studies are warranted to raise awareness of weight issues in FAP and determine the effect of weight loss on FAP.

\section{Background}

Functional gastrointestinal disorders (FGID) are very common clinical conditions encountered in day-today clinical pediatric practice (1). Increased knowledge of the pathophysiology of FGID in the last decade has led to the design of a biopsychosocial model in which genetic, physiological, and psychological factors interact (2). The diagnosis of FGID is clinical and based on the Rome diagnostic criteria, which have evolved during the last decades to form the newest set, the Rome IV criteria which was issued in 2016 (3). Several epidemiological studies using the Rome III and Rome IV criteria showed that FGID related to abdominal pain are highly prevalent $(4,5)$. According to the Rome IV criteria, the term "abdominal pain related functional gastrointestinal disorders" has been changed to "functional abdominal pain disorders" and it includes functional dyspepsia (FD), irritable bowel syndrome (IBS), abdominal migraine, and abdominal pain not otherwise specified (abdominal pain NOS) (3).

Childhood obesity is a serious and urgent public health problem that is associated with physical and psychological comorbidities (6). The association between body weight and FGID has been described in previous studies, however, some of them are limited by a lack of control groups or outdated diagnostic criteria (7-9), and none of them was based on ROME IV criteria. The primary aim of this study was to 
define the association between obesity and subgroups of functional abdominal pain (FAP) disorders in children according to the Rome IV criteria, and to describe and compare clinical characteristics of overweight/obese children with those of normal weight children with FAP disorders.

\section{Methods}

All study procedures were approved by the institutional review board of the Tel Aviv Medical Center (Helsinki Committee).

Study Design and Participants

We conducted a retrospective study of 2- to 18-year-old children with a clinical diagnosis of FAP disorders that were followed-up in the Pediatric Gastroenterology Unit at the "Dana-Dwek" Children's Hospital, Tel Aviv, Israel, between January 2016 and October 2018. Our hospital is a tertiary referral center for pediatric gastroenterology. The patients were identified through the local electronic health records database. FAP disorders were defined according to ROME IV criteria (3). Body mass index (BMI) percentiles were defined by the CDC standards (10). Patients with BMls $\geq 85 \%$ were designated as being overweight or obese. A healthy control group was obtained from the 2015-2016 Israel national health survey of children aged 2-11 years and children aged 12-18 years (11). We excluded children who did not meet the Rome IV criteria and those with missing data.

Data Collection

We retrospectively reviewed the patients' records and collected demographic data consisting of age, gender, location and duration of symptoms (abdominal pain, vomiting, diarrhea, heartburn) as well as anthropometric data (weight, height, BMI). We also reviewed imaging and endoscopies studies, hospitalizations, dietician consultations, nutrition recommendations, and follow-up durations.

Data Statistical Analysis

Categorical variables were reported as frequency and percentage. Continuous variables were evaluated for normal distribution using a histogram. Since none of the continuous variables were normally distributed, they were reported as median and interquartile range (IQR). Overweight proportion was compared to the published data using the one-sample binomial test. Characteristics of overweight and non-overweight children were compared using the Chi-square test or Fisher's exact test for the categorical variables, and the Mann-Whitney test was used for the continuous and ordinal variables. All statistical tests were two-sided, and $p<0.05$ was considered statistically significant. SPSS was used for all statistical analyses (IBM SPSS Statistics, version 25, IBM Corp., Armonk, NY, USA).

\section{Results}

\subsection{Demographic and Clinical Data}


A total of 274 children were identified as having the diagnosis of FAP. Forty-eight children who did not meet the ROME IV criteria and 53 children with missing data were excluded, leaving a total of 173 children for final analysis. Of these children, 114 (65.8\%) were females, and the group's median age was 11.5 (IQR 7.9-14.5) years. The functional disorders were abdominal pain NOS ( $n=71,41 \%)$, IBS $(n=67$, $38.8 \%)$, and FD $(n=35,20.2 \%)$. The median duration of the abdominal pain was 8 months (IQR $4-20)$, the median BMI percentile was 64 (IQR 26.7-86.5), and the median follow-up duration was 2.1 months (IQR 06).

Sixty children (36.4\%) underwent gastroscopy, 13 (7.5\%) underwent colonoscopy, and 132 (76.3\%) underwent imaging studies, of whom $115(66.5 \%)$ had an abdominal ultrasound and $17(9.8 \%)$ had an abdominal computerized tomography or a magnetic resonance enterography. Ninety-nine children $(57.2 \%)$ received medications: $50(28.9 \%)$ were treated with stool softeners, 38 (22\%) with proton pump inhibitors (PPI), and 11 (6.4\%) with probiotics. Twenty children (11.5\%) were hospitalized due to FAP, 46 children $(26.5 \%)$ received dietician consultations and 105 children $(60.6 \%)$ received dietary recommendations from the dietician or physician as follows: high fiber $(n=38,22 \%)$, sugar free $(n=24$, $13.9 \%)$, lactose free $(n=19,11 \%)$, and balanced that included all macronutrients $(n=24,13.9 \%)$.

\subsection{Overweight/obese vs. normal weight in FAP group}

Of all, 53 children (30.6\%) were accounted as overweight/ obese, among them 20 children were obese (37.7\%), 15 (28.3\%) boys and 38 (71.7\%) girls. The distribution among FAP disorders was as follow; 22 (41.5\%) with IBS, 16 (30.2\%) with abdominal pain-NOS and 15 (28.3\%) with FD. Overweight/obese children with FAP disorders were older (12.4 (9.8-15.3) vs. 10.8 (7.4-14.1), $\mathrm{p}=0.04)$, had more hospitalizations due to FAP ( $20.8 \%$ vs. $7.6 \% p=0.01)$, were treated more with PPI $(26.4 \%$ vs. $20 \%, p=0.05)$ and had more dietician consultations ( $43.4 \%$ vs. $19.3 \%, p=0.001)$ compared with FAP children with normal weight. There was a trend for an IBS diagnosis $(41.5 \%$ vs. $37.8 \%, p=0.073)$ in overweight children with FAP disorders. There was no significant difference in gender, endoscopies and imaging studies performance, follow up duration and nutritious recommendations between the groups.

\subsection{The FAP Group vs. the Controls}

The 6432 healthy controls were divided into two age groups, one 2-11 years of age and one 12-18 years of age. The younger age group included 1792 children, of whom 919 (51.3\%) were boys and $873(48.7 \%)$ were girls. There were 299 children (16.7\%) in the young age group who were designated as being overweight/obese. The older age group of 4640 children included $2223(47.9 \%)$ boys and $2417(52 \%)$ girls, among whom 1433 (30.8\%) were designated as being overweight/obese. The 12- to- 18 year old children with FAP had a significantly higher prevalence of overweight/obesity compared to controls $(39.5 \%$ vs. $30 \%$, respectively, $p=0.04)$, and specifically in girls $(42.9 \%$ vs. $29.2 \%, p=0.01)$ in that age range. (Table 1). In addition, the 2- to 11-year-old girls with FAP had a significantly higher prevalence of overweight/obesity compared with the controls in that age range ( $48.7 \%$ vs. $70.6 \%, p=0.04)$ (Table 1$)$. There was no significantly difference in total overweight/obese children and boys in children aged 2-11 years and in boys aged 12-18 years. 


\section{Discussion}

The association between obesity and FAP according to the updated ROME IV criteria had not been investigated before. In the current study, our analysis of that association revealed a higher prevalence of overweight/obesity among children with FAP disorders compared to an age- and sex-matched control population of normal weight FAP children. Our results are in line with studies that had demonstrated a connection between body weight and FGID. Teitelbaum et al (8) showed a greater percentage of obese pediatric patients with constipation, gastroesophageal reflux disease, IBS, encopresis, and FAP compared with normal weight controls. In their study, functional disorders were assigned based on ROME II criteria without specification of subtypes of FAP. Bonilla et al (9) found a $20.2 \%$ prevalence of obesity in patients with FGID, but there was no healthy control group with which to compare their findings. This study showed that obesity is associated with poor outcome and disability at long term follow up. Other studies demonstrated higher percentages of recurrent abdominal pain (12) and FGID (7) in obese children. However, the first study, a non validated questionnaire was used and the latter was based on ROME III criteria for diagnosis of functional disorders.

Several factors may explain the association between obesity and FAP disorders. Dietary habits are a major factor in obesity development and previous studies showed the association between increased consumption of carbohydrates and high body weight $(13,14,15)$. Carbohydrate malabsorption may cause gastrointestinal symptoms via the physiologic effects of both increased osmotic activity and increased gas production from bacterial fermentation (16). Moreover, there is some evidence that a lowFODMAP diet is effective in reducing IBS symptoms $(17,18)$. Recently, Schnabel et al showed an association between ultra-processed food (UPF) consumption and functional gastrointestinal disorders. In this large French cohort, an increase in UPF, which is characterized by high density of saturated fatty acids, sugar, sodium and low content of protective nutrients such as fibers, was associated with a higher risk of IBS. They also found that UPF consumption was associated with higher BMI. (19).

A potential association between obesity, FGID and gastrointestinal motility disorders has also been described. Delayed gastric emptying and impaired antral motility were found in children with RAP, FAP, IBS or functional dyspepsia $(20,21)$. Several studies have shown delayed gastric emptying and gastric and gallbladder dysmotility in obese individuals $(22,23)$. This may be attributed to increased gastric distention in obese causing poor fundal and antral tone (24), altered sensitivity of mechanoreceptors in the stomach musculature (25) and abnormal perception of satiety signals (26).

Another association between obesity and FGID is the gut microbiota. Increased risk of small intestinal bacterial overgrowth (27) and different gut microbiota composition (28) in obesity has been reported which might contribute to gastrointestinal dysmotility, excessive fermentation, altered visceral perception and gut permeability with their metabolites leading to pain-predominant $\operatorname{FGID}(29,30)$.Finally, obesity and FGID share common psychological comorbidities, such as stress, depression, and anxiety, which can contribute to each other's development and aggravate each other $(31,32,33)$. 
Our study has demonstrated a few significant differences between overweight/obese FAP children and normal weight FAP children. We found that overweight/obese FAP children had more hospitalizations attributed to their abdominal pain compared with normal weight FAP children as described in other studies which suggested that pediatric obesity contributes significantly to increased health care utilization in children $(34,35)$.

We also found that obese FAP children are treated more frequently with PPI than normal weight FAP children. Overuse of PPI has been increasing in the last decade in hospitalized and ambulatory patients and their prescription continues to grow in all western countries (36).

The clinical implications of our current study findings relate to the management of overweight/obese children with FGID. They advocate that the treatment protocol of these children should be focused on guidance for nutritional assessment targeted towards weight loss together with other lifestyle changes (e.g., increase in physical activities) that may improve symptoms and prevent or at least minimize the need for medications and hospitalizations.

To the best of our knowledge, this is the first study to show an association between obesity and FAP diagnosed in children according to the updated ROME IV criteria for diagnosis of FAP which was made by a pediatric gastroenterologist in a clinic setting and not by collecting information from a selfadministered questionnaire. This study is limited by its retrospective nature, missing more precise data on skinfold measurements, body composition, and other parameters. In addition, our control group might include children with FAP disorders, although we believe that due to the high number of children included, the percentage of children with FAP disorders would be similar to the general population.

\section{Conclusions}

Children with FAP disorders have a higher prevalence of overweight/obesity compared with healthy controls in the general population. Overweight/obese children with FAP disorders have more hospitalizations and medical treatment with PPI compared to children with FAP disorders who are of normal weight. Heightened awareness of these findings might improve treatment planning and management to meet the needs of overweight/obese children with FAP.

\section{Abbreviations}

FAP- Functional abdominal pain

BMI- Body mass index

IBS- irritable bowel syndrome

FGID- Functional gastrointestinal disorders

FD- functional dyspepsia 
NOS- not otherwise specified

IQR- interquartile range

PPI- proton pump inhibitors

\section{Declarations}

\section{Ethics approval and consent to participate}

All study procedures were approved by the institutional review board of the Tel Aviv Medical Center (Helsinki Committee)

\section{Consent for publication}

"Not applicable"

\section{Availability of data and materials}

- The datasets used and/or analysed during the current study are available from the corresponding author on reasonable request.

\section{Competing interests}

The authors declare that they have no competing interests

\section{Funding}

No funding to declare.

\section{Authors' contributions}

TG and AYF formulated the research question, designed the study, analysed the data, and wrote the manuscript. DL is the registered dietician in this study; SC supervised the statistical analysis, and revised the manuscript. All authors critically reviewed the manuscript and approved the final version submitted for publication.

Short title: Obesity in children with functional abdominal pain

\section{References}

1. Rouster AS, Karpinski AC, Silver D, Monagas J, Hyman PE. Functional gastrointestinal disorders dominate pediatric gastroenterology outpatient practice. J Pediatr Gastroenterol Nutr 2016;62:847851. 
2. Korterink J, Devanarayana NM, Rajindrajith S, Vlieger A, Benninga MA. Childhood functional abdominal pain: mechanisms and management. Nat Rev Gastroenterol Hepatol 2015;12:159-171.

3. Rasquin A, Di Lorenzo C, Forbes D, Guiraldes E, Hyams JS, Staiano A, et al. Childhood functional gastrointestinal disorders: child/adolescent. Gastroenterology 2016;150:1456-1468.

4. Devanarayana NM, Rajindrajith S, Perera MS, Nishanthanie SW, Karunanayake A, Benninga MA. Association between functional gastrointestinal diseases and exposure to abuse in teenagers. $J$ Trop Pediatr 2014;60:386-392.

5. Saps M, Velasco-Benitez CA, Langshaw AH, Ramírez-Hernández CR. Prevalence of functional gastrointestinal disorders in children and adolescents: comparison between Rome III and Rome IV criteria. J Pediatr 2018;199:212-216.

6. Sanders RH, Han A, Baker JS, Cobley S. Childhood obesity and its physical and psychological comorbidities: a systematic review of Australian children and adolescents. Eur J Pediatr 2015; 174:715746.

7. Tambucci R, Quitadamo P, Ambrosi M, De Angelis P, Angelino G, Stagi S, et al. Association between obesity/overweight and functional gastrointestinal disorders in children. J Pediatr Gastroenterol Nutr 2019; 68:517-520.

8. Teitelbaum JE, Sinha P, Micale M, Yeung S, Jaeger J. Obesity is related to multiple functional abdominal diseases. J Pediatr 2009; 154:444-446.

9. Bonilla S, Wang D, Saps M. Obesity predicts persistence of pain in children with functional gastrointestinal disorders. Int J Obes (Lond) 2011; 35:517-521.

10. https://www.cdc.gov/growthcharts/clinical_charts.htm

11. https://www.health.gov.il/UnitsOffice/ICDC/mabat/Pages/default.aspx

12. Malaty HM, Abudayyeh S, Fraley K, Graham DY, Gilger MA, Hollier DR. Recurrent abdominal pain in school children: effect of obesity and diet. Acta Paediatr 2007; 96:572-576.

13. Emmett PM, Jones LR. Diet, growth, and obesity development throughout childhood in the Avon Longitudinal Study of Parents and Children. Nutr Rev 2015; 73:175-206.

14. Te Morenga L, Mallard S, Mann J. Dietary sugars and body weight: systematic review and metaanalyses of randomised controlled trials and cohort studies. BMJ 2012 15; 346: e7492.

15. Dello Russo M, Ahrens W, De Henauw S, Eiben G, Hebestreit A, Kourides Y, et al. IDEFICS Consortium. The Impact of Adding Sugars to Milk and Fruit on Adiposity and Diet Quality in Children: A CrossSectional and Longitudinal Analysis of the Identification and Prevention of Dietary- and LifestyleInduced Health Effects in Children and Infants (IDEFICS) Study. Nutrients. 2018; 21;10:1350.

16. Chumpitazi BP, Shulman RJ. Dietary Carbohydrates and Childhood Functional Abdominal Pain. Ann Nutr Metab 2016; 68:8-17.

17. Shepherd SJ, Lomer MC, Gibson PR. Short-chain carbohydrates and functional gastrointestinal disorders. Am J Gastroenterol 2013; 108:707-17. 
18. Staudacher HM, Whelan K, Irving PM, Lomer MC. Comparison of symptom response following advice for a diet low in fermentable carbohydrates (FODMAPs) versus standard dietary advice in patients with irritable bowel syndrome. J Hum Nutr Diet 2011; 24:487-495.

19. Schnabel L, Buscail C , Sabate JM, Bouchoucha M, Kesse-Guyot E, Allès B, et al. Association Between Ultra-Processed Food Consumption and Functional Gastrointestinal Disorders: Results From the French NutriNet-Santé Cohort. JPGN 2013; 57: 141-148.

20. Devanarayana NM, Rajindrajith S, Bandara C, Shashiprabha G, Benninga MA. Ultrasonographic assessment of liquid gastric emptying and antral motility according to the subtypes of irritable bowel syndrome in children. J Pediatr Gastroenterol Nutr 2013; 56(4):443-448.

21. Devanarayana NM, Rajindrajith S, Perera MS, Nishanthanie SW, Benninga MA. Gastric emptying and antral motility parameters in children with functional dyspepsia: association with symptom severity. J Gastroenterol Hepatol 2013; 28:1161-1166.

22. Di Ciaula A, Wang DQ, Portincasa P. Gallbladder and gastric motility in obese newborns, preadolescents and adults. J Gastroenterol Hepatol 2012; 27:1298-1305.

23. Jackson SJ, Leahy FE, McGowan AA, Bluck LJ, Coward WA, Jebb SA. Delayed gastric emptying in the obese: an assessment using the non-invasive (13) C-octanoic acid breath test. Diabetes Obes Metab 2004; 6:264-270.

24. Horowitz M, Collins PJ, Cook DJ, Harding PE, Shearman DJ. Abnormalities of gastric emptying in obese patients. Int J Obes. 1983;7:415-421.

25. Maddox A, Horowitz M, Wishart J, Collins P. Gastric and oesophageal emptying in obesity. Scand J Gastroenterol 1989; 24:593-598.

26. Horowitz M, Collins PJ, Shearman DJ. Effect of increasing the caloric/osmotic content of the liquid component of a mixed solid and liquid meal on gastric emptying in obese subjects. Hum Nutr Clin Nutr1 986; 40:51-56.

27. Roland BC, Lee D, Miller LS, Vegesna A, Yolken R, Severance E, et al. Obesity increases the risk of small intestinal bacterial overgrowth (SIBO). Neurogastroenterology\&Motility 2018;3:e13199.

28. Hou YP, He QQ, Ouyang HM, Peng HS, Wang Q, Li J, et al. Human Gut Microbiota Associated with Obesity in Chinese Children and Adolescents. Biomed Res Int.2017; 758598.

29. Rhee, S. H., Pothoulakis, C. \& Mayer, E. A. Principles and clinical implications of the brain-gutenteric microbiota axis. Rev. Gastroenterol. Hepatol. 2009; 6:306-314

30. Ohman, L. \& Simren, M. Intestinal microbiota and its role in irritable bowel syndrome (IBS). Curr Gastroenterol Rep 2013; 15: 323.

31. Topçu S, Orhon FŞ, Tayfun M, Uçaktürk SA, Demirel F. Anxiety, depression and self-esteem levels in obese children: a case-control study. J Pediatr Endocrinol Metab 2016; 29:357-361.

32. Shin NY, Shin MS. Body dissatisfaction, self-esteem, and depression in obese Korean children. $J$ Pediatr2008;152: 502-506. 
33. CampoJV, Gilchrist RH. Psychiatric comorbidity and functional abdominal pain. Pediatr Ann 2009; 38:283-287.

34. Hampl SE, Carroll CA, Simon SD, Sharma V. Resource utilization and expenditures for overweight and obese children. Arch Pediatr Adolesc Med. 2007; 161:11-14.

35. Trasande L, Chatterjee S. The impact of obesity on health service utilization and costs in childhood. Obesity.2009; 17:1749-1754.

36. Lanas A. We Are Using Too Many PPIs, and We Need to Stop: A European Perspective. Am J Gastroentero/2016; 111:1085-1086.

\section{Table}

Table 1. Overweight Patients in the FAP and Control Groups by Age and Gender 


\begin{tabular}{|c|c|c|c|}
\hline P Value & $\begin{array}{r}\begin{array}{r}\text { Control } \\
\mathrm{N}=4640\end{array} \\
\end{array}$ & $\begin{array}{l}\text { FAP group } \\
\qquad \mathrm{N}=81\end{array}$ & Children $12-18$ years old \\
\hline 0.04 & $1433(30.8)$ & $32(39.5)$ & $\begin{array}{l}\text { Total overweight/obese } \\
\mathrm{n}(\%)\end{array}$ \\
\hline 0.44 & $\begin{array}{l}2223(47.9) \\
726(32.6)\end{array}$ & $\begin{array}{l}32(39.5) \\
11(34.4)\end{array}$ & $\begin{array}{l}\text { Boys, n(\% of total) } \\
\text { overweight/obese } \\
\text { n (\%) }\end{array}$ \\
\hline 0.01 & $\begin{array}{l}2417(52) \\
707(29.2)\end{array}$ & $\begin{array}{l}49(60.4) \\
21(42.9)\end{array}$ & $\begin{array}{l}\text { Girls, n (\% of total) } \\
\text { Overweight/obese } \\
\text { n (\% of girls) }\end{array}$ \\
\hline P Value & Control N=1792 & $\begin{array}{l}\text { FAP group } \\
\qquad \mathrm{N}=92\end{array}$ & Children 2-11 years old \\
\hline 0.07 & $299(16.7)$ & $21(22.8)$ & $\begin{array}{l}\text { Total overweight/obese } \\
\mathrm{n}(\%)\end{array}$ \\
\hline 0.5 & $\begin{array}{l}919(51.3) \\
148(16.1)\end{array}$ & $\begin{array}{l}27(29.3) \\
4(14.8)\end{array}$ & $\begin{array}{l}\text { Boys, } \mathrm{n}(\% \text { of total) } \\
\text { overweight/obese } \\
\mathrm{n}(\%)\end{array}$ \\
\hline 0.04 & $\begin{array}{l}873(48.7) \\
151(17.3)\end{array}$ & $\begin{array}{l}65(70.6) \\
17(26.2)\end{array}$ & $\begin{array}{l}\text { Girls, n (\% of total) } \\
\text { Overweight/obese } \\
\text { n (\% of girls) }\end{array}$ \\
\hline
\end{tabular}

